\title{
Costovertebral and costotransverse joint involvement in rheumatoid arthritis
}

\author{
MICHAEL J. COHEN, JOAN EZEKIEL, AND ROBERT H. PERSELLIN \\ From the Division of Rheumatology, Department of Medicine, and the Department of Radiology, The University \\ of Texas Health Science Center at San Antonio, USA
}

SUMMARY Lesions of the costovertebral (CV) and costotransverse (CT) joints are distinctly unusual in rheumatoid arthritis. The patient presented had dramatic changes in these joints with destruction, ankylosis, and bony overgrowth. This led to a moderate respiratory impairment and a distinctive radiological presentation.

The costovertebral (CV) and costotransverse (CT) joints are diarthrodial joints containing hyaline articular cartilage and lined with synovial membrane and can be involved in inflammatory joint disease (Goldthwait, 1940; Dihlman and Frik, 1968; Zimmer, 1968; Jaffe, 1972). However, lesions of the ribs and their articulations with the vertebral column are rare. The following is a case with unique involvement of the CV and CT joints which has not been previously described.

\section{Case report}

The patient, a 28 year old, Mexican-American female, was admitted to Bexar County Hospital because of an exacerbation of her arthritis. She had a 5-year history of symmetrical polyarthritis involving peripheral joints with morning stiffness and high titre rheumatoid factor.

On admission the patient complained of pain and limitation of motion of all major joints and pain along the medial border of the scapulae. She specifically denied dyspnoea on exertion or chest pain, but did admit to prolonged morning stiffness and fatigue.

Physical examination revealed a thin women in moderate distress due to active synovitis. There was mild micrognathia and tender temporomandibular joints. There was full range of motion of the cervical spine, but some tenderness was elicited over the spinous process of $\mathrm{C7}$. There was mild tenderness on

Accepted for publication January 10, 1978

Correspondence to $\mathrm{Dr}$ Michael J. Cohen, Division of Rheumatology, Department of Medicine, The University of Texas Health Science Center at San Antonio, 7703 Floyd Curl Drive, San Antonio, Texas 78284, USA. palpation near the medial borders of the scapulae. Chest expansion measured at the fourth intercostal space was $1.5 \mathrm{~cm}$. She had diffuse tenderness of multiple peripheral joints. There was extensive atrophy of the muscles of the hands. Erythema and tenderness were detected over the right achilles tendon. There were no rheumatoid nodules.

The haematocrit was 38 with a white blood cell count of $4900 / \mathrm{mm}^{3}$. The erythrocyte sedimentation rate was $50 \mathrm{~mm} / \mathrm{hr}$ (Westergren); a sensitised sheep cell agglutination titre was positive at 1:3584, and an RA slide latex (Hyland) was $4+$ positive (Cheng and Persellin, 1971). The antinuclear antibody fluorescence test was positive and serum anti-DNA binding was negative (Kredich et al., 1973). HLA typing revealed A2, A28, B16, and BW40. Pulmonary function testing showed a moderate to severe restrictive ventilatory defect. Nerve conduction in the forearms and wrists was normal.

Chest radiology showed bulb-like lesions in the region of the CT joints bilaterally. There was bony overgrowth and ankylosis of the CT joints of ribs $5,6,7$, and 8 on the left and 5, 6, and 7 on the right. There was also involvement of the adjacent CV joints which was best seen on tomograms. A dorsal lordotic view detailed this involvement of both CV and CT joints (Fig. 1). In addition, a small erosion of the superior margin of the posterior part of the left third rib was noted. The involved ribs were enlarged and the cortices extending from the CV and CT joints were thickened. The involved ribs were $33 \%$ wider at a point $5 \mathrm{~cm}$ from the midline compared to the uninvolved ribs. There was irregularity of the joint margin of the third and fourth left CT joints. Juxta-articular demineralisation and small erosions were noted at the radial aspect of the left third and 


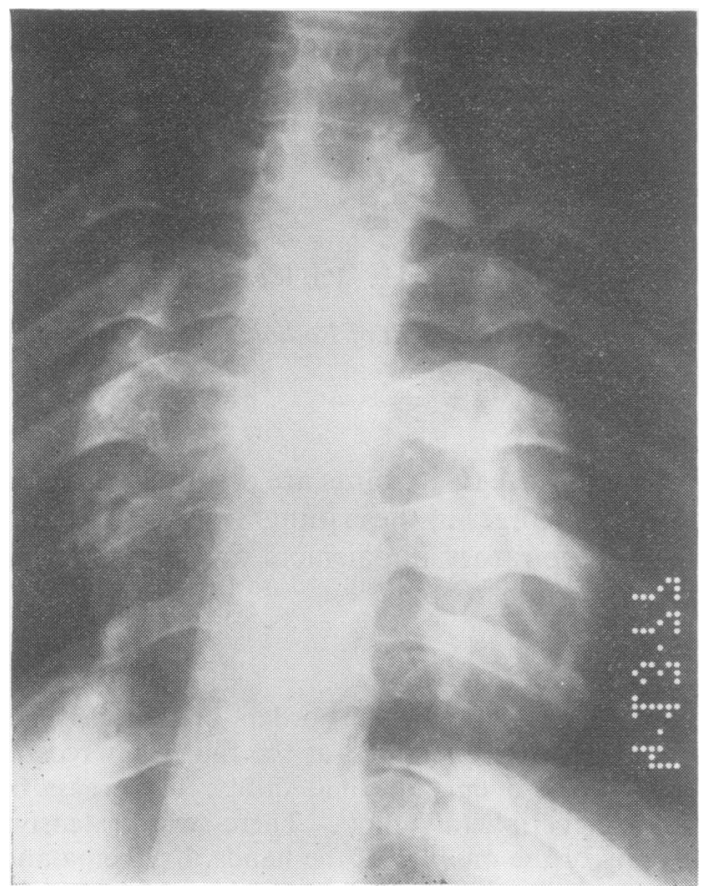

Fig. 1 Dorsal lordotic view (technique of Williams (1949) and of Hohman and Gasteiger (1970)) which demonstrates enlargement and ankylosis of the costotransverse and costovertebral joints bilaterally.

fourth and the right third and fourth proximal interphalangeal joints. Cervical spine, thoracic spine, and lumbosacral spine films showed only mild apophyseal sclerosis at $T_{11}-T_{12}$, but no changes of ankylosing spondylitis or degenerative joint disease. Rib notching was not found and the sacroiliac joints were normal.

After 7 days in hospital on high dose salicylate therapy, the patient developed chills, nausea, and malaise. SGOT was 855 IU, SGPT 644 IU alkaline phosphatase $136 \mathrm{IU}$, and bilirubin $0.4 \mathrm{mg} / 100 \mathrm{ml}$ $(6.8 \mu \mathrm{mol} / \mathrm{l})$. The buffered aspirin was stopped and ibuprofen (Motrin) was substituted. Several days later these symptoms subsided and 1 week later the SGOT was $50 \mathrm{IU}$, SGPT $161 \mathrm{IU}$, alkaline phosphatase $130 \mathrm{IU}$, and bilirubin $0.2 \mathrm{mg} / 100 \mathrm{ml}(3.4$ $\mu \mathrm{mol} / \mathrm{l})$. Hepatitis B surface antigen was negative. The articular symptoms improved and she was discharged.

\section{Discussion}

Arthritis of the CT and CV joints is recognised as occurring in ankylosing spondylitis (Dihlman and Frik, 1968; Jaffe, 1972) and degenerative joint disease
(Krauss, 1956; Zimmer, 1968), but has not been widely reported in rheumatoid arthritis (RA). The changes described in association with ankylosing spondylitis include irregularities of joint margigs, periarticular calcification and destruction of joint. These findings are usually seen in conjunction with the more typical axial skeleton changes $\Phi_{\mathrm{f}}$ ankylosing spondylitis and have not been reportedgas occurring alone. Osteophyte formation of these joints has been seen in patients with degeneratiye joint disease. Only a brief comment of CV joint arthritis was made by Bywaters (1974) in a discussion of discitis in RA.

ֻ.

The CV joint consists of the head of the rib aiand facets on the upper and lower edges of the adjacent vertebral bodies at the disc margin, except for the $C V$ joints of $T_{11}$ and $T_{12}$, which do not overridewa disc space. The CT joint consists of the tubercle of the rib and a facet on the anterior or superior surface of the transverse process (Fig. 2). Since both are lined by a synovial membrane and are in const motion, they would be expected to be involved iroa generalised inflammatory arthritis. Perhaps rhewmatoid involvement is overlooked since this area cannot be easily discerned on a routine chest $x$-ray affd special views are required.

The pathological process in our patient appears $\frac{0}{30}$ have been an inflammatory synovitis which led restriction of motion, bony overgrowth and anloglosis of the involved joints (Fig. 2). The bony overgrowth also involved the transverse processes aftd the ribs, which showed an increase in cortical thickness and total diameter extending laterally from the joint. Clinically the patient denied dypsnoea but $\overline{\text { dind }}$ have a restrictive defect on pulmonary function testing.

There are several unusual features of this case. The axial predominance is suggestive of ankylosing spondylitis. However, our patient was female, had normal sacroiliac joints, no other manifestations of ankylosing spondylitis, and was HLA-B27 negati官. Our patient had aspirin hepatotoxicity. Whereas th is more common in the juvenile form of rheumatod arthritis (JRA) (Manso et al, 1956; Russell, 1971 ; Rich and Johnson, 1973; Athreya et al. 1975) it has been observed in the adult form as well (Seaman age Plote, 1976; Wilson, 1976). She had also microe gnathia, suggestive of JRA. The peculiar bo overgrowth seen at the CV and CT joints is reminiscent of the enlarged joints in some JRA patients when inflammatory synovitis occurs near the epiphyseal plate (Ansell and Bywaters, 1956; Martel et aD, 1962)

The diagnosis of rheumatoid arthritis in thin patient was based on the chronic, symmetrical polsarthritis with erosive changes in the small joints gf 


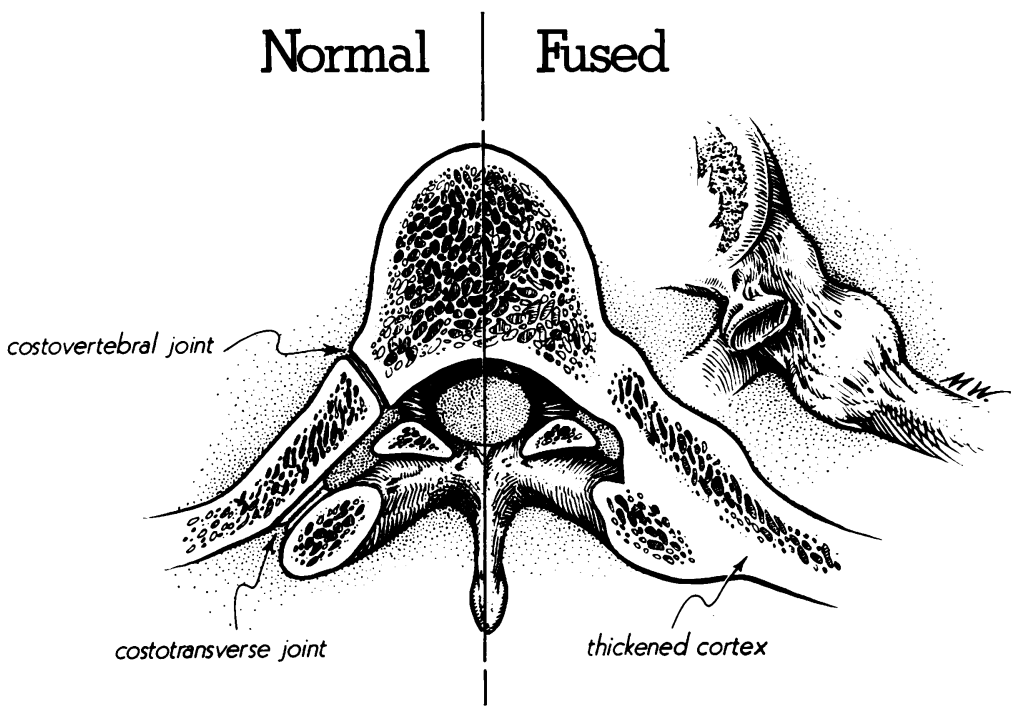

Fig. 2 Artist's conception of a coronal section through a thoracic vertebra showing the diarthrodial costotransverse and costovertebral joints both as they would appear normally (left side of drawing) and as seen in our patient (right side). Depicted is the bony overgrowth, ankylosis of both the $C T$ and $C V$ joints and widening and thickening of the cortex of the rib and joint areas.

the hands, morning stiffness, and the presence of rheumatoid factor. Our patient's chest wall symptoms began at age 22 , before closure of the epiphyses of the ribs. The secondary ossification centers of the rib are at the tubercle and the vertebral epiphyses at the head of the rib. These appear about age 14 but do not fuse until age 25 (Caffey, 1967). Therefore, we conclude that our patient had involvement by adult rheumatoid arthritis of these joints before epiphyseal closure, leading to this surprising and unique radiological picture. The inflammatory changes with ankylosis led to atypical back pain and pulmonary dysfunction.

This study was supported in part by grants from the South Central Texas Chapter of the Arthritis Foundation, The Ruth and Vernon Taylor Foundation of Denver, Colorado, and by a Clinical Research Center grant from The Arthritis Foundation.

\section{References}

Ansell, B. M., and Bywaters, E. G. L. (1956). Growth in Still's disease. Annals of the Rheumatic Diseases, 15, 295316.

Athreya, B. H., Moser, G., and Cecil, H. S. (1975). Aspirin induced hepatotoxicity in juvenile rheumatoid arthritis. Arthritis and Rheumatism, 18, 347-352.

Bywaters, E. G. L. (1974). Rheumatoid discitis in the thoracic region due to spread from costovertebral joints. Annals of the Rheumatic Diseases, 33, 408.

Caffey, J. (1967). Pediatric X-Ray Diagnosis, 5th ed., p. 209. Year Book Medical Publishers: Chicago.

Cheng, C., and Persellin, R. H. (1971). Interference by Clq in slide latex tests for rheumatoid factor. Annals of Internal Medicine, 75, 683-686.

Dihlman, W., and Frik, W. (1968). Spondylitis Ankylopoetica die Bechterwsche Krankheit. Fortchritte auf den Gebiete der Roentgenostrahlen und der Nuklearmedcin, Supp. 100, 29-33.

Goldthwait, J. E. (1940). The rib joints. New England Journal of Medicine, 223, 568-573.

Hohman, D., and Gasteiger, W. (1970). Zür Roentgendiagnostik du Costotransversalgelenke. Fortschritte auf den Gebiete der Roentgenstrahlen und der Nuklearmedcin, 112, 783-789.

Jaffe, H. L. (1972). Metabolic, Degenerative and Inflammatory Diseases of Bone and Joints, p. 828. Lea and Febiger: Philadelphia.

Krauss, V. R. (1956). Die Arthrosis Deformans in den Costotransversalgelenke. Fortschritte auf den Gebiete der Roentgenstrahlen und der Nuklearmedcin, 85, 60-66.

Kredich, N. M., Skyler, J. S., and Fotte, L. J. (1973). Antibodies to native DNA in systemic lupus erythematosus. Archives of Internal Medicine, 131, 639-644.

Manso, C., Taranta, A., and Nydick, I. (1956). Effect of aspirin administration on SGOT and SGPT in children. Proceedings of the Society of Experimental Biology and Medicine, 93, 84-88.

Martel, W., Holt, J. F., and Cassidy, J. T. (1962). Roentgenologic manifestations of juvenile rheumatoid arthritis. American Journal of Roentgenology, Radium Therapy and Nuclear Medicine, 88, 400-423.

Rich, R. R., and Johnson, J. S. (1973). Salicylate hepatotoxicity in patients with juvenile rheumatoid arthritis. Arthritis and Rheumatism, 16, 1-9.

Russell, A. S. (1971). Serum transaminase during salicylate therapy, British Medical Journal, 2, 428-429.

Seaman, W. E., and Plote, P. H. (1976). Effect of ASA on liver tests in patients with RA or SLE and in normal volunteers. Arthritis and Rheumatism, 19, 155-160.

Williams, A. J. (1949). Rheumatoid spondylitis-Technique of examination and importance of the costal joints. California Medicine, 70, 257-261.

Wilson, J. R. (1976). Aspirin hepatotoxicity in adults with rheumatoid arthritis. Ohio State Medical Journal, 72, 577578.

Zimmer, E. A. (1968). Borderlands of the Normal and Early Pathologic in Skeletal Roentgenology, translated and edited by S. P. Wilk, pp. 282-283. Grune and Stratton: New York. 